\title{
Brief Communication: A new testing field for debris flow warning systems
}

\author{
M. Arattano ${ }^{1}$, V. Coviello ${ }^{1}$, M. Cavalli ${ }^{2}$, F. Comiti ${ }^{3}$, P. Macconi ${ }^{4}$, J. Theule ${ }^{3}$, and S. Crema ${ }^{2}$ \\ ${ }^{1}$ Italian National Research Council (CNR), Research Institute for Geo-hydrological Protection (IRPI), Torino, Italy \\ ${ }^{2}$ Italian National Research Council (CNR), Research Institute for Geo-hydrological Protection (IRPI), Padova, Italy \\ ${ }^{3}$ Faculty of Science and Technology, Free University of Bozen-Bolzano, Bolzano, Italy \\ ${ }^{4}$ Department of Hydraulic Engineering, Autonomous Province of Bozen-Bolzano, Bolzano, Italy
}

Correspondence to: V. Coviello (velio.coviello@irpi.cnr.it)

Received: 11 February 2015 - Published in Nat. Hazards Earth Syst. Sci. Discuss.: 2 March 2015

Accepted: 15 June 2015 - Published: 13 July 2015

\begin{abstract}
A permanent field installation for the systematic test of debris flow warning systems and algorithms has been equipped on the eastern Italian Alps. The installation was also designed to produce didactic videos and it may host informative visits. The populace education is essential and should be envisaged in planning any research on hazard mitigation interventions: this new installation responds to this requirement and offers an example of integration between technical and informative needs. The occurrence of a debris flow in 2014 allowed the first tests of a new warning system under development and to record an informative video on its performances. This paper will provide a description of the installation and an account of the first technical and informative results obtained.
\end{abstract}

\section{Introduction}

The prediction and forecasting of landslides is a very broad issue that involves the work of researchers of many different disciplines and includes several diverse topics. The latter holds a place for the early warning of landslides and the study and development of Early Warning Systems (EWSs) (Intrieri et al., 2012; Rose and Hungr, 2007). Restricting further into the topic, a specific theme is represented by the early warning for rapid mass movements such as debris flows (Stähli et al., 2015).

There are two main categories of debris flow EWS, namely the advance and the event EWS (Hungr et al., 1987). Advance EWSs predict the occurrence of a debris flow by mon- itoring the hydro-meteorological conditions that might lead to its initiation (Keefer et al., 1987), whereas event EWSs detect the debris flow when it is already occurring (Badoux et al., 2008).

An event EWS may use different types of detecting devices that range from simple electrified wires, broken by the passage of the flow, to more complex types of sensors that require the development of algorithms to interpret the sensor output and recognize the debris flow occurrence. The devices employed by EWSs are usually the same used for monitoring and research in rheological and modeling studies and investigations on propagation processes. They include a wide variety of sensors, such as stage sensors, seismic sensors, microphones, trip wires, and video cameras (Arattano and Grattoni, 2000; Suwa et al., 2011; Zhang, 1993; Marchi et al., 2002).

The event EWS for debris flows usually detects the passage of a debris flow at a certain cross section where the sensor is installed, but they may also be able to detect some tens of seconds in advance the arrival of the debris flow when ground vibration sensors are employed (Abancó et al., 2014; Koschuch et al., 2015; Schimmel and Hübl, 2015). The event EWS that rely on the use of algorithms to process the monitoring data and recognize the occurrence of a debris-flow event, usually require long development and systematic testing. An instrumented site specifically designed for testing EWSs and their algorithms would be of great help to favor their development and improvement and to increase the sites where researches on EWSs are already being performed (Abancó et al., 2014; Badoux et al., 2008; Koschuch et al., 
2015; Moser et al., 2002). It would also allow to undertake a first attempt toward a standardization of procedures and methods for such testing. The standardization of monitoring and warning procedures for debris flows is in fact a need that is starting to be felt (Arattano et al., 2015). All these needs suggested to equip a specific testing field for event EWSs and warning algorithms in the instrumented area of the Gadria creek, on the north-eastern Italian Alps.

The installation of a testing field for debris flow EWS is also important because it may increase the public awareness on their functionality and effective performances. An EWS, in fact, cannot provide complete safety for the people that it is devoted to protect, as a certain percentage of risk will always remain and false alarms will also be possible. Therefore the interested population needs to learn and understand the performance of an EWS and the service it may provide. The Gadria testing field, other than providing educational videos as it will be shown in the following, might be used for guided visits that could connect public and researchers and to help reach such an understanding more easily.

\section{The Gadria testing field for debris flow warning algorithms}

Any EWS needs a period of calibration and tests that precedes its operational employment. This is particularly true for the event EWS that makes use of warning algorithms to process the output of the sensors employed for detection. In fact, the warning algorithms are required to be systematically and extensively checked for verifying their capacity in correctly detecting the occurrence of a debris flow and measuring the needed parameters. The warning algorithms that require that a certain signal intensity threshold is exceeded to spread the alarm, for example, need a check of the correct choice of the threshold (Badoux et al., 2008). The check must include the capability of the algorithm to avoid the detection of other types of phenomena that might produce false alarms (Coviello et al., 2015). Moreover, algorithms might need improvement on the basis of their first performances and also the improved versions should undergo a systematic phase of tests.

These needs have suggested the realization of a specific facility where the required tests could systematically be performed with the needed recurrence and continuity. The ideal location of such an installation would have been an already existing instrumented area for debris flow monitoring where events occurred with a high enough frequency to grant the possibility of a significant number of tests. The Gadria catchment, located in the eastern Italian Alps provided a good opportunity. Information concerning the Gadria catchment, its past debris flows and its monitoring installations can be found in Comiti et al. (2014).

The testing field has been realized in 2014 along a straight reach of the Gadria creek (Fig. 1). Downstream of this reach

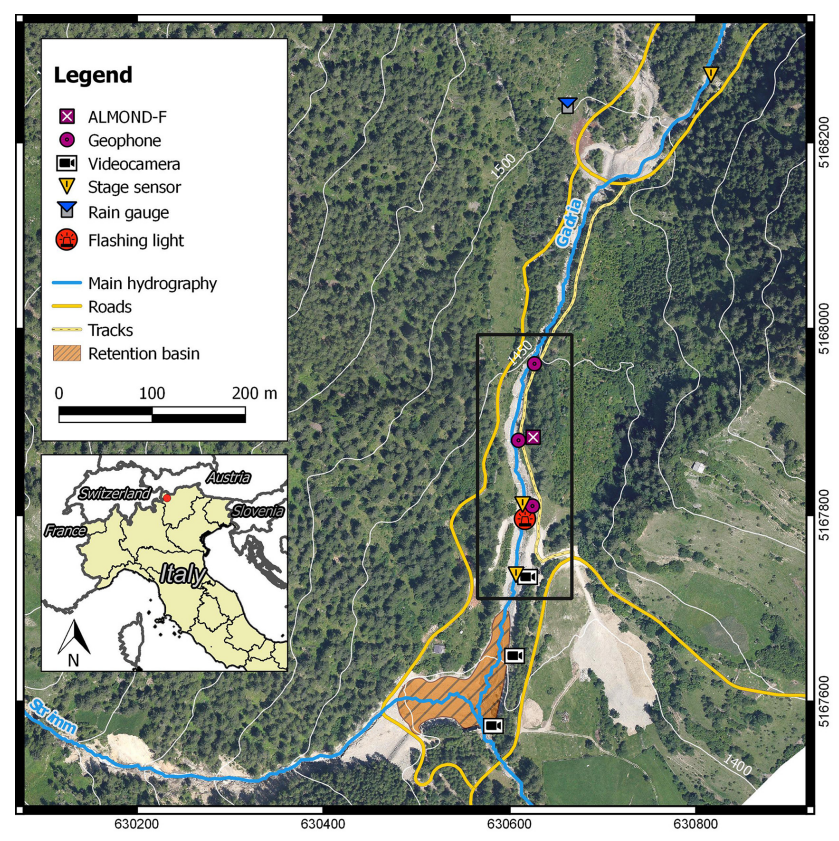

Figure 1. The Gadria testing field (black rectangle) for debrisflow warning systems and algorithms. Background image coordinate system: WGS 1984 UTM Zone 32N.

there is a deposition basin where the debris flows generally stop completely. At the downstream end of this basin a slit check dam allows the passage of water and finer sediments. The deposition basin is periodically mechanically emptied. Few kilometers downstream of the check dam there are some roads, bridges and a small village located in the proximity of the channel. Despite the presence of the retention basin, some residual risk still exists: a large debris flow event could exceed the capacity of the retention basin, especially in the case that it is not empty.

The chosen reach was already equipped with different types of sensors for the monitoring of debris flows (Comiti et al., 2014), including rain gauges, three video cameras shooting the channel, two radars for flow stage measurements and four geophones. The downstream boundary of the testing field is determined by the most upstream of the fixed video cameras. This video camera (Fig. 2a) is in fact an essential part of the EWS testing field installation, as it will be shown in the following paragraphs.

About $150 \mathrm{~m}$ upstream of the video camera, a specific equipment was installed (Fig. 2b) that has been designed by the CNR IRPI researchers and constructed by the Company SIAP+MICROS, which also contributed to fund the research along with the EU-funded SedAlp project. This equipment is named ALMOND-F, which stands for ALarm and MONitoring system for Debris-Flows. The ALMOND-F is designed to host different types of sensors, including pendulums, radar and ultrasonic sensors, but was particularly intended for the seismic detection of debris flows. In fact, when connected 

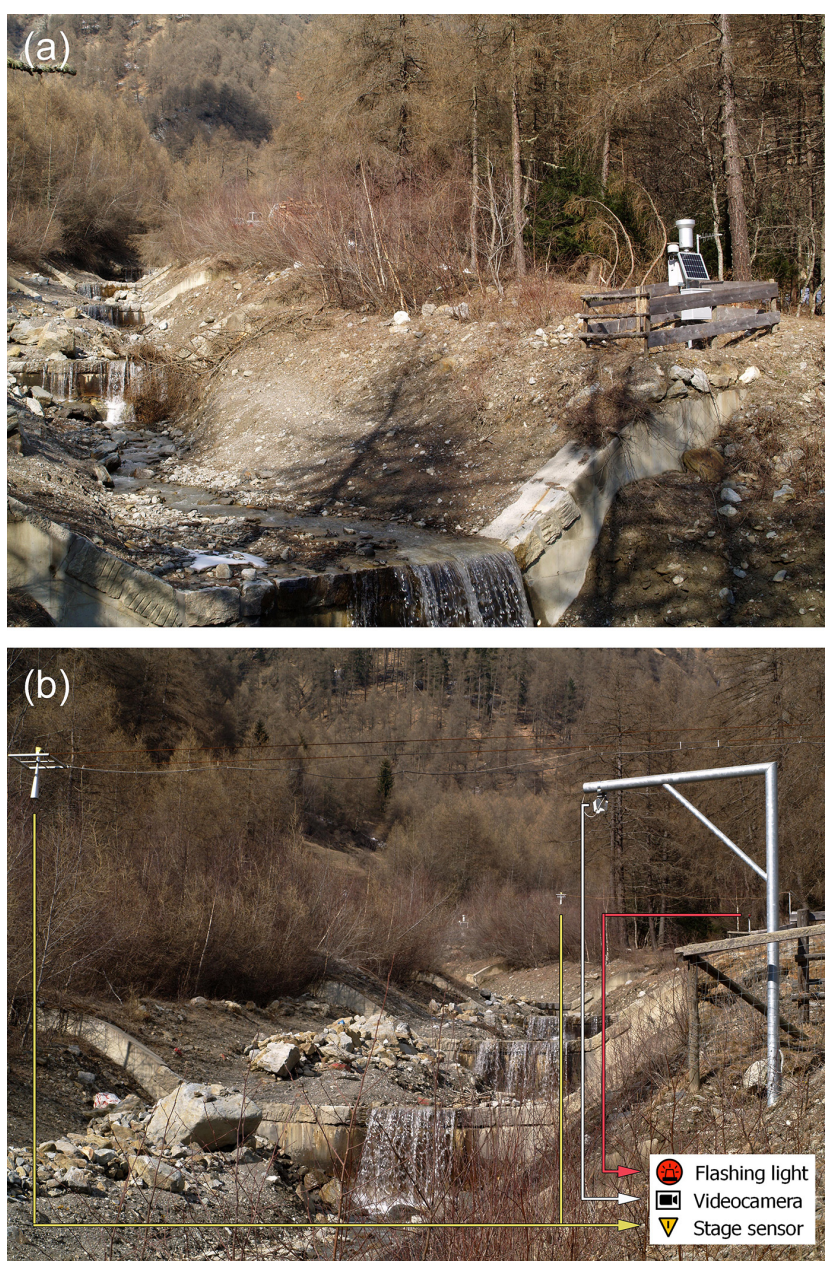

Figure 2. (a) The ALMOND-F equipment installed on the left bank of the Gadria torrent including a rain gauge, a solar panel and the box containing the data logger; (b) the area downstream the ALMOND-F: the video camera visible in this picture shot the frames reported in Fig. 3.

to geophone sensors, the system allows to set different values of signal amplification (gain range 1-128) for each geophone. This permits the installation of the geophones also at great distance from the torrent, according to the specific morphologic conditions that may be found in the field. The ALMOND-F automatically samples the geophone signal at a frequency of $128 \mathrm{~Hz}$ and then calculate the signal Amplitude directly on board. It may implement different warning algorithms aboard that can be directly uploaded with a laptop computer. Finally, a flashing light (Fig. 2) has been installed on the bank of the torrent $75 \mathrm{~m}$ downstream of the ALMOND-F equipment and has been cabled together.

The flashing light is framed by the fixed video camera (Fig. 1) and is activated by the algorithm. This allows a visual verification of the efficacy of the algorithm under test. The activation of the flashing light is in fact recorded by the video camera, which also records the arrival of the debris flow. By analyzing the video recordings, it is possible to verify the moment when the light starts to flash and the contemporary occurrence of the debris flow. When the warning system is capable of providing an alarm in advance, as it occurs when it makes use of seismic sensors (Abancó et al., 2014), it becomes possible to appreciate visually the amount of time elapsed between the activation of the flashing light and the actual arrival of the debris flow.

An event EWS may also have a closure algorithm which recognizes when the event is finished and turns off the alarm. This would correspond to the restoring of the green light in case the EWS were connected to a traffic light to stop the vehicles and impede the access to an endangered stretch of road or railways. The flashing light of the Gadria EWS testing field also permits an easy check of such closure algorithms, visualizing the turning off of the flashing light and the correspondent flow that is occurring in the channel at that moment.

\section{An educational and informative site}

The shooting of videos that show the activation and deactivation of the flashing light was specifically intended to show the performances of an EWS to decision makers, practitioners and the general public and to make them aware of its functionality. The involvement and the education of the interested populace are important goals and essential steps in almost any hazard mitigation activity. These goals should not be pursued as something separated by the research activities carried out in the field or in the laboratory. On the contrary, they should be kept in mind during all of the phases of the research and possibly integrated within the research activity.

The Gadria testing field was designed with this in mind and can be considered a first attempt of such an integration. In fact, it has an importance and a utility that goes beyond the simple mechanical test of new algorithms. This latter, in fact, might have been pursued from a mere technical point of view, without the need of a video camera and a flashing light, but by simply designing and installing the ALMOND-F equipment and then analyzing the recorded data in a laboratory. The installation of a flashing light framed by a video camera, however, makes the functionality of a warning system and its performances much more evident and understandable. Decision makers, practitioners and the general public could not analyze complex files of data and the formulas of an algorithm, but can certainly recognize if a flashing light was correctly activated and then if it was correctly turned off.

The Gadria testing field, thanks to the described structure, is therefore an important source of didactic videos (Dutto et al., 2015). It is also a possible destination for educational trips, carried out for information and divulgation purposes, and it may be a font of news that can be published on popular magazines widely circulated, as it has recently occurred (Bignami, 2015). 


\section{First tests performed in the Gadria EWS testing field}

The Gadria EWS testing field has provided a chance, in 2014, to test a new warning algorithm, developed by the researchers of CNR IRPI. The algorithm is designed to detect debris flows through the use of geophones. A first version of the algorithm, which uses the signal-to-noise Ratio (SNR) as a warning parameter instead of the usual threshold of the signal intensity (see Abancó et al., 2014 and Badoux et al., 2008), was implemented aboard the alarm and monitoring unit of the Gadria EWS testing field at the beginning of the 2014 summer season. The SNR was chosen as a warning parameter to investigate the possibility to detect earlier the arrival of the debris flow than only using a threshold of the signal intensity. The results obtained for the 2014 event seem to support this possibility.

The warning algorithm processes the amplitude signal provided by three vertical $1-\mathrm{D}, 10-\mathrm{Hz}$ geophones. These geophones are installed at three different locations, some tens of meters apart along the channel (Fig. 1) and connected to the ALMOND-F equipment that records the data. The warning algorithm makes use of the signal of three geophones to reduce the possibility of false alarms. It is in fact required by the algorithm that a certain site-specific threshold of the SNR is exceeded on at least two geophones to issue the alarm (turn on the flashing light). The amplitude has been preferred to the method of impulses as a method to process the seismic signal, to avoid the difficulties posed by the choice of the threshold for the impulse calculations (Arattano et al., 2014).

On 15 July 2014 a debris flow occurred in the Gadria creek and provided a chance for the test of the warning algorithm. Both the opening and closure algorithms performed well. The recorded video shows the activation of the flashing light about $3 \mathrm{~min}$ before the arrival of the debris flow main front. When the flashing light turned on, the Gadria Creek was affected by a turbulent wave with intense bed load transport. After the passage of the eight surges composing the debris flow event, the flashing light was correctly turned off, as it is possible to observe in the recorded images (Fig. 3). No other surge followed the turning off of the flashing light.

Within the 51 days of tests carried out during the 2014 summer season, two false alarms were detected by the system. One was likely produced by the passage of a vehicle along the track located on the left bank of the torrent (Fig. 1) and the other by a distant source of vibration that caused simultaneous recordings at the three sensors. The relative data were recorded by the monitoring equipment. The recorded video of the July debris flow event and the monitoring data concerning the false alarms have provided precious information regarding the performances of the algorithm. The latter will be consequently improved to reach better performances and reduce the number of false alarms. The improvements are currently under development and an improved version of the algorithm is actually under test. Moreover, another monitoring equipment composed by one geophone and an infra-

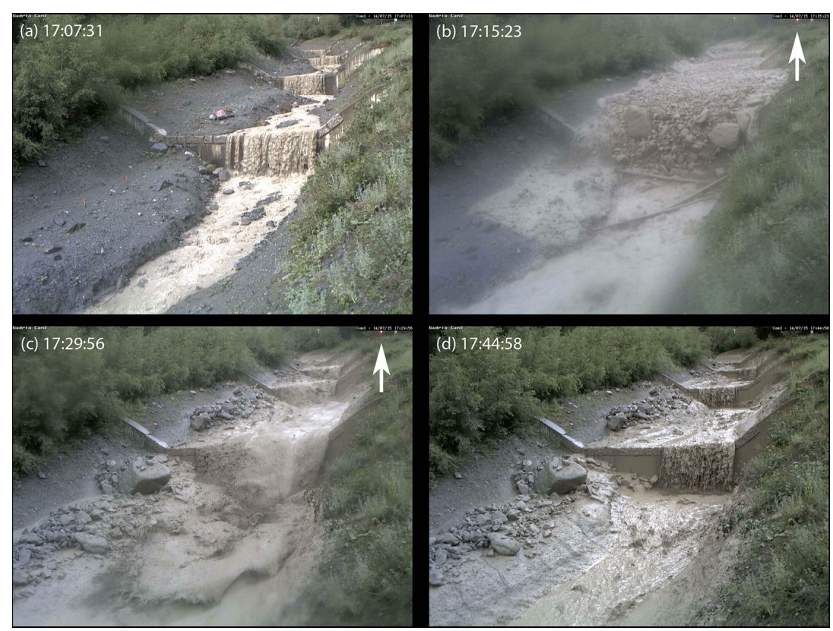

Figure 3. Frames from the video camera part of the EWS testing field (Fig. 2b) showing the debris flow occurred on 15 July 2014 in the Gadria creek. Time in the upper-left corner of each frame is in UTC +1 (local time). The closure algorithm correctly turned off the flashing light at the end of the process: (a) the creek before the process (flashing light off); (b) arrival of the main front (flashing light on, as pointed out by the white arrow); (c) a secondary surge (flashing light still on); (d) the end of the process (flashing light off).

sound sensor (Schimmel and Hübl, 2015) was recently installed in the Gadria testing field by the researchers of BOKU University. This equipment was developed for warning purposes and is expected to contribute to the development and testing of other types of debris flow warning algorithms.

\section{Conclusions}

A testing field for debris flow warning systems has been instrumented in the Gadria basin. The installation provides a site where different types of warning systems and algorithms for debris flows can be tested. It encompasses a specifically designed alarm and monitoring equipment that can be linked to different types of sensors and implement different algorithms aboard. A flashing light framed by a video camera and activated by the algorithm under test permits a visual verification of the performance of this latter. The importance of the installation is also due to the chance that it may offer to increase the public awareness about the functioning of an EWS and the hazard mitigation that it may allow. This goal could be pursued through the realization of didactic videos, guided visits and the spreading of informative news on the debris flow events that occur in the Gadria Creek. So far, such instrumented basin has provided some first important indications for the enhancement of the algorithms currently under investigation. 
Acknowledgements. This study is funded by the European Territorial Cooperation Alpine Space Programme 2007-2013 SedAlp project, by the Autonomous Province of Bolzano and by the Company SIAP+MICROS S.r.l. The monitoring station of the Gadria basin is managed by the Autonomous Province of Bozen-Bolzano (Department of Hydraulic Engineering).

Edited by: F. Catani

Reviewed by: two anonymous referees

\section{References}

Abancó, C., Hürlimann, M., and Moya, J.: Analysis of the ground vibration generated by debris flows and other torrential processes at the Rebaixader monitoring site (Central Pyrenees, Spain), Nat. Hazards Earth Syst. Sci., 14, 929-943, doi:10.5194/nhess-14929-2014, 2014.

Arattano, M., Abancó, C., Coviello, V., and Hürlimann, M.: Processing the ground vibration signal produced by debris flows: the methods of amplitude and impulses compared, Comput. Geosci., 73, 17-27, doi:10.1016/j.cageo.2014.08.005, 2014.

Arattano, M., Cavalli, M., Comiti, F., Coviello, V., Macconi, P., and Marchi, L.: Standardization of methods and procedures for debris flow seismic monitoring, in: Engineering Geology for Society and Territory - Volume 3, edited by: Lollino, G., Arattano, M., Rinaldi, M., Giustolisi, O., Marechal, J.-C., and Grant, G. E., 6367, Springer International Publishing, Switzerland, 2015.

Arattano, M. and Grattoni, P.: Using a fixed video camera to measure debris-flow surface velocity, in: Second International Conference on Debris-flow Hazards Mitigation: Mechanics, Prediction, and Assessment, edited by: Wieczorek, G. F. and Naeser, N. D., 16-18, Balkema, Rotterdam, Taipei, 2000.

Badoux, A., Graf, C., Rhyner, J., Kuntner, R., and McArdell, B. W.: A debris-flow alarm system for the Alpine Illgraben catchment: design and performance, Nat. Hazards, 49, 517-539, doi:10.1007/s11069-008-9303-x, 2008.

Bignami, L.: Droni, fibre ottiche, sensori chimici: i metodi per prevenire crolli e smottamenti sono sempre più efficaci, Focus (Madison), 104-108, 2015.

Comiti, F., Marchi, L., Macconi, P., Arattano, M., Bertoldi, G., Borga, M., Brardinoni, F., Cavalli, M., D’Agostino, V., Penna, D., and Theule, J.: A new monitoring station for debris flows in the European Alps: first observations in the Gadria basin, Nat. Hazards, 73, 1175-1198, doi:10.1007/s11069-014-1088-5, 2014.

Coviello, V., Arattano, M., and Turconi, L.: Detecting torrential processes from a distance with a seismic monitoring network, Nat. Hazards, doi:10.1007/s11069-015-1819-2, in press, 2015.

Dutto, F., Arattano, M., Bacenetti, M., Chiarle, M., Contrafatto, C., Giardino, M., Longo, F., Perotti, L., Racca, F., Rocci, L. and Turconi, L.: Interactive, 3D Simulation of Natural Instability Processes for Civil Protection Purposes, in: Engineering Geology for Society and Territory - Volume 7, edited by: Lollino, G., Arattano, M., Giardino, M., Oliveira, R., and Peppoloni, S., 125-130, Springer International Publishing, Switzerland, 2015.
Hungr, O., Morgan, G. C., VanDine, D. F., and Lister, D. R.: Debris flow defenses in British Columbia, in: Debris Flows/Avalanches: Process, Recognition, and Mitigation, vol. 7, edited by: Costa, J. E. and Wieczorek, G. F., 201-222, Geological Society of America, 1987.

Intrieri, E., Gigli, G., Mugnai, F., Fanti, R., and Casagli, N.: Design and implementation of a landslide early warning system, Eng. Geol., 147-148, 124-136, doi:10.1016/j.enggeo.2012.07.017, 2012.

Keefer, D. K., Wilson, R. C., Mark, R. K., Brabb, E. E., Brown, W. M., Ellen, S. D., Harp, E. L., Wieczorek, G. F., Alger, C. S., and Zatkin, R. S.: Real-time landslide warning during heavy rainfall, Science, 238, 921-925, doi:10.1126/science.238.4829.921, 1987.

Koschuch, R., Jocham, P., and Hübl, J.: One Year Use of HighFrequency RADAR Technology in Alpine Mass Movement Monitoring: Principles and Performance for Torrential Activities, in: Engineering Geology for Society and Territory - Volume 3, edited by: Lollino, G., Arattano, M., Rinaldi, M., Giustolisi, O., Marechal, J.-C., and Grant, G. E., 69-72, Springer International Publishing, Switzerland, 2015.

Marchi, L., Arattano, M., and Deganutti, A. M.: Ten years of debrisflow monitoring in the Moscardo Torrent (Italian Alps), Geomorphology, 46, 1-17, doi:10.1016/S0169-555X(01)00162-3, 2002.

Moser, M., Pichler, A., Hübl, J., Ganahl, E., and Steinwendtner, H.: Transfer from a monitoring system to an early warning system?: development of a debris flow warning system at Wartschenbach (Eastern Tyrol, Austria ), in: ERB and Northern European FRIEND Project 5 Conference, Demänovská dolina, Slovakia, 2002.

Rose, N. D. and Hungr, O.: Forecasting potential rock slope failure in open pit mines using the inverse-velocity method, Int. J. Rock Mech. Min. Sci., 44, 308-320, doi:10.1016/j.ijrmms.2006.07.014, 2007.

Schimmel, A. and Hübl, J.: Approach for an Early Warning System for Debris Flow Based on Acoustic Signals, in: Engineering Geology for Society and Territory - Volume 3, edited by: Lollino, G., Arattano, M., Rinaldi, M., Giustolisi, O., Marechal, J.-C., and Grant, G. E., 55-58, Springer International Publishing, Switzerland, 2015.

Stähli, M., Sättele, M., Huggel, C., McArdell, B. W., Lehmann, P., Van Herwijnen, A., Berne, A., Schleiss, M., Ferrari, A., Kos, A., Or, D., and Springman, S. M.: Monitoring and prediction in early warning systems for rapid mass movements, Nat. Hazards Earth Syst. Sci., 15, 905-917, doi:10.5194/nhess-15-905-2015, 2015.

Suwa, H., Okano, K., and Kanno, T.: Forty years of debrisflow monitoring at Kamikamihorizawa Creek, Mount Yakedake, Japan, in: 5th International Conference on Debris-Flow Hazards Mitigation: Mechanics, Prediction and Assessment, edited by: Genevois, R., Hamilton, D. L., and Prestininzi, A., 605-613, Casa Editrice Università La Sapienza, Roma, 2011.

Zhang, S.: A Comprehensive Approach to the Observation and Prevention of Debris Flows in China, Nat. Hazards, 7, 1-23, doi:10.1007/BF00595676, 1993. 